the commonest indentifiable allele has a frequency no greater than 0.99 and therefore the proportion of heterozygotes is at least two per cent of the population. It is difficult to account for the high prevalence of such polymorphisms and the author presents a very readable account of the problem. It might, of course, turn out that most of these variations are no more than "random noise", but it is difficult to accept that this could be the entire explanation.

Altogether this is a fine book which can be unreservedly recommended as a graduate student text as well as a work of reference. Of course, because of the enormous growth of the subject, this new edition might now appeal more to the specialist. Perhaps for a more general readership Professor Harris could be persuaded to produce a basic text similar to his Introduction to Human Biochemical Genetics which was published some 22 years ago by Cambridge University Press and which was the progenitor of the current text.

Alan E.H. Emery is Professor of Human Genetics in the Medical School of Edinburgh University.

\title{
Where psychology meets biology
}

\section{J. Morgan}

Essay on Mind. By D. O. Hebb. Pp.159. (Lawrence Erlbaum Associates: 1980.) $\$ 16.50$.

IN THIS “essay", Professor Hebb expresses in clear and forceful language his conviction that ". . . mind and thought, consciousness and creativity and free will, are all biologically evident phenomena and seen most clearly in the light of evolutionary ideas". He summarizes the historical development of his own "cell assembly" theory, familiar from his classic book The Organization of Behaviour (Wiley, 1949) and to a certain extent attempts to relate it to modern developments in neurophysiology and psychology. There is little here that is very new, but $\mathrm{Hebb}$ was one of the first to argue that psychology is largely a biological subject, at a time when it was neither profitable nor popular. The gritty style of this book makes few concessions to the subtleties of professional philosophy, and somehow manages to convey the general impression that objections would be unwise and illinformed, if not actually silly. Fortunately, no one need feel too offended by this brusque treatment, because the counterarguments are put into the mouths of anonymous "writers", rather than being attributed to specific people.

On the heredity-environment issue Hebb neatly clears up some common confusions, and expresses the view that extreme environmentalism can have morally dangerous effects. It is pleasing to see the boot on the other foot for a change: usually it is environmentalists who assume the mantle of moral superiority. Returning to a theme familiar from his Textbook (W. B. Saunders, 1972) Hebb warns the young student that if he has an inherited predisposition to alcoholism, he had better recognize it quickly and take appropriate avoiding action. This he is not likely to do ". . . if he takes it for granted that all men are born equal . . . and seeing others drink freely without becoming drunks, takes it for granted that he can do the same". This is probably good advice, certainly no worse than that given by people who think that it is wicked to believe in genes.

The "cell-assembly" model can now be seen as one of the first "feature analysis" models of perception. Its essence is that cells or groups of cells coding for distinctive features such as lines are grouped together into superordinate assemblies by associative learning. These assemblies can in turn be grouped into assemblies representing concepts, and so on, presumably up to "grandmother assemblies", which would be activated when we were thinking of a particular person. Hebb notes that the physiological work of Hubel and Wiesel has given considerable support to this idea since he first produced it, but he quotes their hierarchical model as if it were established fact, without mentioning important criticisms. $\mathrm{He}$ also attempts to extend the theory in a way that many readers will probably find frankly metaphorical: we read, for example, that "Emotion is a disruption of cell assemblies".

The experiments that $\mathrm{Hebb}$ pioneered at McGill on effects of early environment in animals are given prominence and still raise issues of great interest. But as in the case of the discussions of visual perception, it is disappointing not to be presented with any more recent data, particularly those concerning effects of early environment on synaptic connections.

Possibly the most interesting aspect of this book is the historical insight it gives into the process by which $\mathrm{Hebb}$ arrived at his theory at a time when radical behaviourism made any physiological theorizing disreputable. That many of these early battles will now seem a bit outdated to the younger generation of psychologists is a measure of Hebb's success in helping to win them.

M. J. Morgan is Professor of Psychology at the University of Durham.
ISSN-0275-4207

THE BIOTECHNOLOGY NEWS SOURCE ${ }^{\text {TM }}$

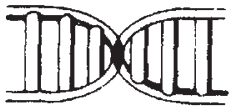

BioEngineering News -

the only biweekly

newsletter covering the

genetic-engineering

recombinant-DNA, monoclonal-antibody, and cell-culture industries.

\section{4 issues - $\$ 236.00$ (U.S.) (\$195.00 in U.S. \& Canada) \\ Subscriptions sent airmail.}

Write: BioEngineering News, Suite 304, 109 Minna St., San Francisco, CA 94105. Tel: (415) 332-0508. Telex: 171463-HQLARK.

Special Reports Available: (1) Genetic Engineering Industry, (2) $\mathrm{Hy}$ bridoma \& Cell Fusion, (3) Auto. mated DNA Synthesizers. Price: $\$ 29.95$ (U.S. Funds).

NOTE . For prepaid subscriptions select any two (2) reports as a bonus.

Circle No. 16 on Reader Enquiry Card.

\section{The ANS Journals}

Your number one source for current intor mation on the nuclear industry.

- NUCLEAR NEWS (NN) - NUCLEAR SCIENCE NUCLFAR TECHNOLOGY(NT) ENGINEERING (NS\&E) - NUCLEAR TECHNOLOGY FUSION (NT/F)

- NUCLEAR STANDARDS -TRANSACTIDNS (TR) NEWS (NSN)

- ANSPI (ANSPI

-REMOTE SYSTEMS TECHNOLOGY (RSTD)

(Write for our complete publications catalng.)

Send To:

AMERICAN NUCLEAR SOCIETY 555 N. Kensington Avenue

La Grange Park, IL 60525 USA

Please send me information on

$$
\begin{aligned}
& \text { NN I INS\&E INT I.. NT/F } \\
& \text { INSN I ITR ARSTO ANSP } \\
& \text { National Meetings L : Topical Meetings } \\
& \text { IIndividual Membership L Corporation Membership } \\
& \text { Send me your free catalog }
\end{aligned}
$$

Circle No.11 on Reader Enquiry Card.

NAME

TITLE

ORGANIZATION

ADDRESS

CITY

STATE ZIP 